\title{
Os gêneros Cyclolejeunea, Haplolejeunea, Harpalejeunea, Lepidolejeunea e Rectolejeunea (Lejeuneaceae, Hepaticae) na Estação Científica Ferreira Penna, Pará, Brasil
}

\author{
Anna Luiza Ilkiu-Borges ${ }^{1,2}$ e Regina Célia Lobato Lisboa ${ }^{1}$
}

Recebido em 25/02/2003. Aceito em 14/01/2004

\begin{abstract}
RESUMO - (Os gêneros Cyclolejeunea, Haplolejeunea, Harpalejeunea, Lepidolejeunea e Rectolejeunea (Lejeuneaceae, Hepaticae) na Estação Científica Ferreira Penna, Pará, Brasil). Com o objetivo de contribuir para o conhecimento da família Lejeuneaceae no Estado do Pará, realizou-se o levantamento da mesma na Estação Científica Ferreira Penna, onde foi observada a ocorrência de sete espécies pertencentes a Cyclolejeunea, Haplolejeunea, Harpalejeunea, Lepidolejeunea e Rectolejeunea. Todas as espécies estão descritas, ilustradas e separadas por chaves artificiais, com comentários adicionais.
\end{abstract}

Palavras-chave: Briófitas, hepáticas, Lejeuneaceae, Pará

\begin{abstract}
The Cyclolejeunea, Haplolejeunea, Harpalejeunea, Lepidolejeunea and Rectolejeunea genera (Lejeuneaceae, Hepaticae) in the Ferreira Penna Research Station, Pará, Brazil). The aim of this study was to contribute to the knowledge of the Lejeuneaceae from State of Pará. Therefore a survey was performed at Ferreira Penna Research Station, where the occurrence of seven species was observed belonging to the genera Cyclolejeunea, Haplolejeunea, Harpalejeunea, Lepidolejeunea and Rectolejeunea. The species are described, illustrated and separated by artificial keys with additional commentaries.
\end{abstract}

Key words: Bryophytes, liverworts, Lejeuneaceae, Pará

\section{Introdução}

O mais extenso trabalho sobre as hepáticas na região amazônica, incluindo a família Lejeuneaceae, foi o de Spruce (1884-1885), resultado de 15 anos de coletas durante a primeira metade do século XIX. Esse é um trabalho de referência para a região neotropical, principalmente em relação à tribo Lejeuneae, cuja classificação é ainda adotada para muitos táxons e os subgêneros que propôs para Lejeunea, foram elevados a gêneros que levam esses nomes.

No Brasil, inúmeros trabalhos colaboraram para o conhecimento da família Lejeuneaceae, destacando-se os de Bastos et al. (1998a; 1998b; 2000), Bastos \& Bôas-Bastos (2000a; 2000b), Bastos \& Yano (2002), Baptista (1977), Behar et al. (1992), Bescherelle (1893), Bôas \& Bastos (1998), Costa (1992), Costa \& Yano (1998), Germano \& Pôrto (1998), Giancotti \& Vital (1989), Oliveira e Silva (1998), Oliveira e Silva \& Yano (1998), Pôrto (1989; 1990), Pôrto \& Grolle (1987), Pôrto et al. (1999), ReinerDrehwald \& Gradstein (1995), Reiner-Drehwald \&
Schäfer-Verwimp (1996), Schäfer-Verwimp (1991; 1992), Visnadi (1998), Visnadi \& Monteiro (1990), Visnadi \& Vital (1995); Vital et al. (1991), e Yano (1984a; 1987; 1989; 1993; 1995; 1996), Yano \& Andrade-Lima (1987). Desses, a grande maioria trata sobre as espécies das regiões Nordeste, Sudeste e Sul do Brasil.

Até o levantamento realizado na ECFPn (IlkiuBorges 2000; Ilkiu-Borges \& Lisboa 2002a; 2000b; 2000c), entre os estudos realizados na região Norte que incluíam Lejeuneaceae, destacavam-se os de Griffin III (1979), Gradstein (1978), Lisboa (1976; 1985), Lisboa \& Ilkiu-Borges (1995), Lisboa \& Nazaré (1997), Lisboa \& Yano (1987), Vital \& Visnadi (1994), Yano \& Lisboa (1988) e Yano \& Mello (1992). Entretanto, somente os trabalhos de Gradstein (1978) e Griffin III (1979) apresentaram descrição ou chave para a identificação de espécies.

Esses dados confirmam o lento avanço dos estudos sobre Lejeuneaceae na Amazônia Brasileira. Para o estudo dessa família na região, o que muito tem contribuído, além dos trabalhos realizados nas outras

\footnotetext{
Museu Paraense Emílio Goeldi, Departamento de Botânica, C. Postal 399, CEP 66040-170, Belém, PA, Brasil

2 Autor para correspondência: ilkiuborges@yahoo.com.br
} 
regiões do Brasil que dão condições para a identificação de espécies, são aqueles realizados em outros países, como Evans (1902; 1903a; 1903b; 1904; 1905; 1906; 1907a; 1907b; 1908; 1911; 1912), Schuster (1980), Lücking (1995), Reiner-Drehwald (1993; 1994; 1995a; 1995b; 1998), e, principalmente, as revisões de tribos e gêneros, como por exemplo Bischler (1964; 1967; 1968; 1969), Gradstein (1994), He (1999), He \& Grolle (2001), Piippo (1986) e Reiner-Drehwald \& Goda (2000).

A partir de Gradstein \& Costa (2003), as dificuldades para a identificação das espécies de Lejeuneaceae no Brasil serão menores. Nesse trabalho, é feito extenso levantamento sobre todas as famílias de hepáticas e antóceros citados para o Brasil, além de novas ocorrências, sinônimos e chaves para identificação. Além dos autores, esse estudo conta com a colaboração de especialistas em diversos gêneros, enriquecendo e atualizando o conhecimento sobre esses grupos.

Com o objetivo de contribuir para o conhecimento da família Lejeuneaceae do Estado do Pará, foi realizado inventário dessa família na Estação Científica Ferreira Penna, município de Melgaço. Aqui são tratadas sete espécies pertencentes aos gêneros Cyclolejeunea A.Evans, Haplolejeunea Grolle, Harpalejeunea (Spruce) Steph., Lepidolejeunea Schuster e Rectolejeunea A.Evans.

\section{Material e métodos}

O material estudado foi coletado na Estação Científica Ferreira Penna (ECFPn), localizada na Floresta Nacional de Caxiuanã, município de Melgaço, Pará, Brasil.

A coleta de material seguiu as técnicas adotadas em Yano (1984b) e Lisboa (1993), e as espécies foram classificadas de acordo com os tipos de substratos onde foram coletadas: corticícola (tronco vivo), epíxila (árvore morta e epífila) e epífila (folha viva).

Para a identificação foi utilizada bibliografia especializada e/ou realizada a comparação com espécimes identificados por especialistas.

As descrições das espécies foram baseadas no material encontrado e, portanto, nem todas incluem a descrição das estruturas reprodutivas, por estarem ausentes no material coletado.

As exsicatas estão depositadas no Herbário “João Murça Pires”(MG), do Museu Paraense Emílio Goeldi.

\section{Resultados e discussão}

Na Estação Científica Ferreira Penna (ECFPn), foram coletadas sete espécies dos gêneros Cyclolejeunea, Haplolejeunea, Harpalejeunea, Lepidolejeunea e Rectolejeunea, pertencentes à tribo Lejeuneae Dumort. da família Lejeuneaceae Casares-Gil.

Chave artificial para os gêneros coletados

1. Ocelos incolores espalhados pelos filídios, lóbulos, anfigastros, brácteas, bractéolas e perianto

2. Lóbulo com ápice arredondado, sem dente apical, papila hialina posicionada internamente no ápice, nem distal, nem proximal; perianto com duas quilhas III. Haplolejeunea

2. Lóbulo com dente apical formado por uma célula alongada, fracamente falcada, papila hialina proximal; perianto com cinco quilhas IV. Lepidolejeunea

1. Ocelos presentes apenas nos filídios

3. Plantas com filídios caducos; 2-3 ocelos na base do filídio, maiores que as células adjacentes, e inúmeros ocelos adicionais dispersos pelo lobo, pouco maiores que as células adjacentes

3. Ausência de filídios caducos, ocelos basais ou supra-basais presentes, ocelos espalhados pelo filídio ausentes

4. Plantas com gemas discóides ou ovaladas com rizóides marginais, filídios com ápice obtuso a agudo I. Cyclolejeunea

4. Gemas ausentes, filídios com ápice acuminado ou piliforme, com 2-7 células em fileira II. Harpalejeunea 


\section{Cyclolejeunea A.Evans}

Cyclolejeunea foi descrito por Evans (1904), assim como quatro de suas espécies, com ilustrações e discussões. Esse gênero ocorre somente na região Neotropical, onde suas espécies crescem como epífilas ou corticícolas em troncos e galhos de florestas tropicais úmidas de planície a montanhosas (Bernecker-Lücking 1998). Essas plantas apresentam alta variabilidade morfológica, o que ocasionou a descrição de cerca de 35 espécies, muitas das quais foram sinonimizadas por Grolle (1984a). Posteriormente, Bernecker-Lücking (1998) estudou Cyclolejeunea na Costa Rica apresentaram descrição, ilustração e comentário de cinco espécies. Atualmente, considera-se que esse gênero apresente apenas de seis a sete espécies neotropicais (Gradstein et al. 2001).

As espécies de Cyclolejeunea são caracterizadas pelas margens dos filídios denteadas a crenuladas, periantos com duas quilhas laterais aladas, uma inovação do tipo pycnolejeuneóide e gemas que se desenvolvem na margem anterior dos filídios (Bernecker-Lücking 1998).

Chave artificial para as espécies de Cyclolejeunea

1. Filídios com 350-1000 $\mu \mathrm{m} \times 240-650 \mu \mathrm{m}$, ápice agudo, margens inteiras a serreado-denticuladas; anfigastros inteiros a brevemente bífidos; gemas discóides

1. Filídios com 210-350 $\mu \mathrm{m} \times 180-300 \mu \mathrm{m}$, ápice obtuso a fracamente agudo, margens inteiras a denticuladas; anfigastros bífidos; gemas ovaladas ou oblongo-ovaladas

\section{C. luteola}

1. Cyclolejeunea convexistipa (Lehmann \& Lindenberg) A. Evans, Bull. Torrey Bot. Club, 31: 198. 1904.

Jungermannia convexistipa Lehmann \& Lindenberg, Lehmann, Nov. Stirp. Pugillus, 6: 43. 1834. Tipo: Lesser Antilles, St. Vicent. In monte Sancti Andreae, hb Hooker (lectótipo, BM, designado por Grolle, 1984a).

Fig. 1.

Gametófitos verde-pálidos a castanho-enegrecidos (mais velhos), prostrados, fortemente aderidos ao substrato, muito ramificados, às vezes com ramos ascendentes, geralmente com filídios menores, 20-30×0,8-2,1mm. Caulídio em secção transversal com
7-10 células epidérmicas circundando 7-11 células medulares menores; merófito ventral com 2 células de largura. Ocelos incolores, 1-2 por filídio, suprabasais, dispostos lado a lado, geralmente maiores que as células adjacentes. Filídios ovalado-falcados, imbricados, com 350-1.000×240-650 $\mu \mathrm{m}$, ápice agudo a obtuso, margem antical fortemente arqueada, margem posterior mais ou menos reta, geralmente com um entalhe na junção com a quilha do lóbulo, margens inteiras a serreadodenticuladas; células isodiamétrica-romboidais,

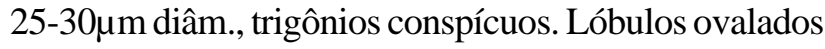
a sub-retangulares, inflados, $100-350 \times 60-250 \mu \mathrm{m}$, margem livre involuta na base, dente apical unicelular, curto, orbicular a levemente alongado e falcado, papila hialina proximal. Anfigastros distantes a imbricados, sub-orbiculares, inteiros a brevemente bífidos, $150-450 \times 200-450 \mu \mathrm{m}$, margens inteiras a serreadodenteadas, linha de inserção mais ou menos reta. Gemas discóides, produzidas pelas células da margem anterior dos filídios, com incisão marginal no lado oposto a região apical e rizóides marginais curvados sobre a superfície da lâmina celular. Androécio terminal ou em ramos curtos, com 6-15 pares de brácteas, 2-3 bractéolas na base do perigônio. Ginoécio terminal ou em ramos curtos especializados, com uma inovação do tipo pycnolejeuneóide, fértil ou não, brácteas oblongas a obovadas, de tamanhos diferentes, ápice obtuso a agudo, margens inteiras a serreado-denteadas, lóbulos obovado-lanceolados, bractéola obovada, geralmente 2 vezes o comprimento de um anfigastro, brevemente bífida a inteira, cobrindo até a metade do perianto ou acima. Perianto piriforme, 450-500x $400-450 \mu \mathrm{m}$, com 2 quilhas laterais, explanadas, aladas e eretas, margens geralmente serreadas a serreadodenteadas, rostro conspícuo. Esporófito não observado.

Distribuição geográfica: México, Guatemala, Honduras, Costa Rica, Panamá, Cuba, Jamaica, República Dominicana, Porto Rico, Guadalupe, Dominica, Martinica, St. Vicent, Colômbia, Venezuela, Guiana, Suriname, Guiana Francesa, Equador, Peru e Brasil (Lücking 1995). No Brasil é mencionada para os Estados do AM, AP, PA e SP (Yano 1984a; 1989).

Discussão: essa é uma espécie epífila ou corticícola, amplamente distribuída na região neotropical (Evans 1904). Na ECFPn essa espécie é preferencialmente epífila em ecossistema de várzea e de terra firme, raramente corticícola ou epíxila. É caracterizada, principalmente, pelos anfigastros geralmente inteiros e pelas gemas discóides ainda aderidas ao filídio ou soltas na lâmina preparada para identificação. As margens dos filídios e anfigastros 

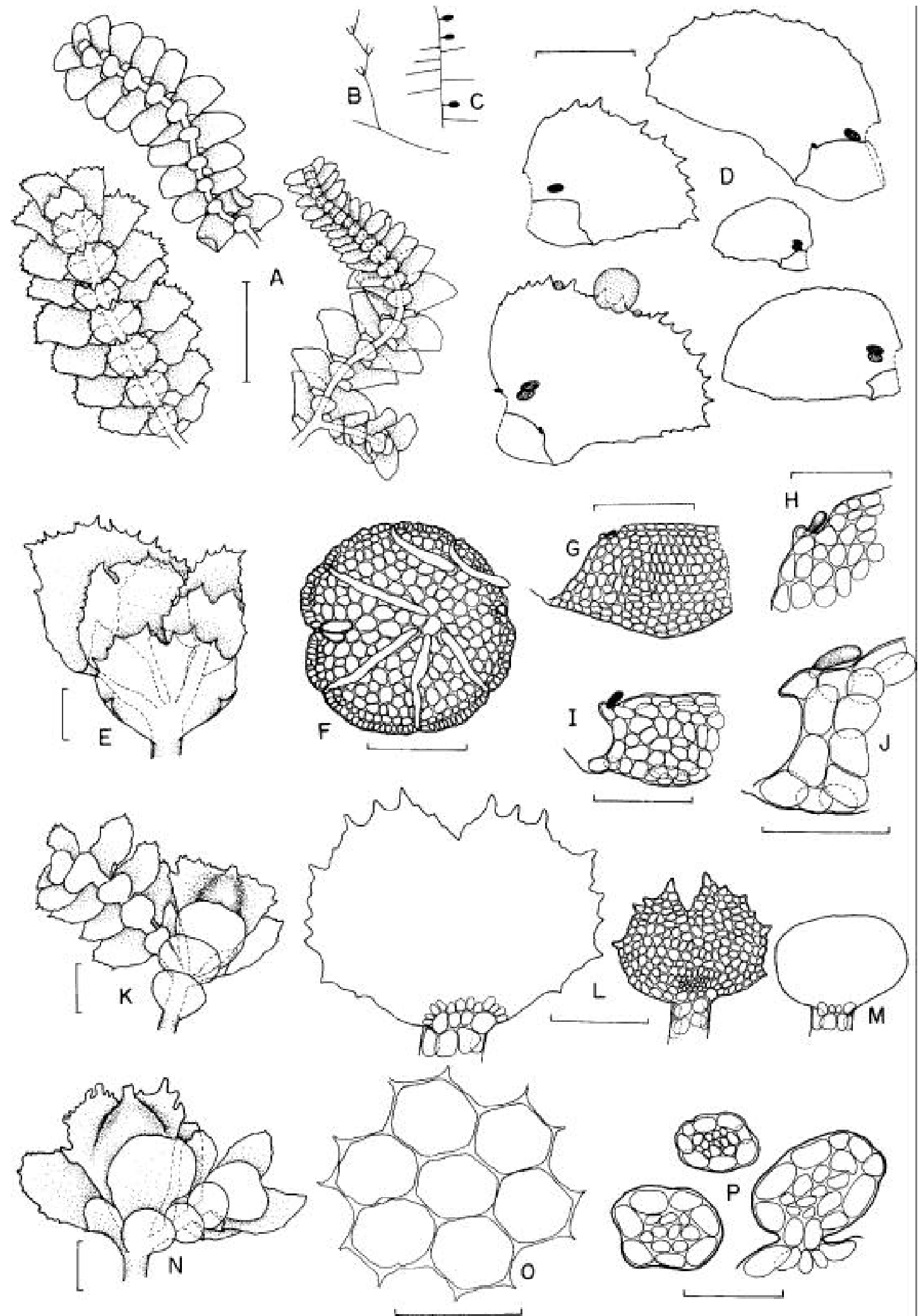

Figura 1. Cyclolejeunea convexistipa (Lehmann \& Lindenberg) A. Evans. A. Hábitos, vista ventral. B-C. Esquema de plantas férteis $(\bullet=$ androceu, $\mathrm{O}=$ gineceu). D. Cinco exemplos de filídios. E. Ginoécio. F. Gema. G. Lóbulo. H. Detalhe do ápice do lóbulo com papila hialina. I. Lóbulo. J. Detalhe do ápice do lóbulo com papila hialina. K. Perianto com inovação. L-M. Anfigastros. N. Perianto. O. Células da região

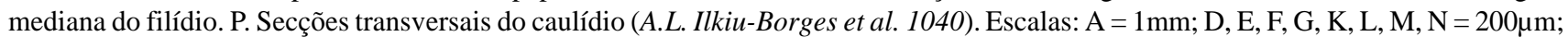
$\mathrm{H}, \mathrm{I}, \mathrm{P}=100 \mu \mathrm{m} ; \mathrm{J}, \mathrm{O}=50 \mu \mathrm{m}$. 
podem variar de inteiras a serreado-denticuladas no mesmo espécime. Os ramos secundários apresentam filídios e anfigastros geralmente menores, fortemente imbricados, com margens serreado-denticuladas.

Material examinado: BRASIL. Pará: Melgaço, ECFPn, 29/XI/1997, várzea, epífila, A.L. Ilkiu-Borges et al. 874 (MG); idem, A.L. Ilkiu-Borges et al. 876 (MG); idem, A.L. Ilkiu-Borges et al. 878 (MG); idem, 2/XII/1997, terra firme, epífila, A.L. Ilkiu-Borges et al. 881 (MG); idem, A.L. Ilkiu-Borges et al. 882 (MG); idem, 8/XII/1997, várzea, epíxila, A.L. Ilkiu-Borges et al. 1025 (MG); idem, corticícola, A.L. Ilkiu-Borges et al. 1040 (MG); idem, epífila, A.L. Ilkiu-Borges et al. 1052 (MG); idem, A.L. Ilkiu-Borges et al. 1080 (MG); idem, A.L. Ilkiu-Borges et al. 1107 (MG); idem, A.L. Ilkiu-Borges et al. 1134 (MG); idem, 1/XI/1996, terra firme, epífila, R. Lisboa et al. 6033 (MG).

2. Cyclolejeunea luteola (Spruce) Grolle, Wiss. Zeitschr. Friedrich-Schiller-Univ. Jena, Math.-Nat. Reihe, 33: 761. 1984.

Lejeunea (Cerato-lejeunea) luteola Spruce, Trans. Proc. Bot. Soc. Edinburgh, 15: 205. 1884. Tipo: Venezuela. Amazonas, Rio Negro, San Carlos, Spruce L 407 (lectótipo, MANCH, designado por Grolle, 1984a).

Fig. 2.

Gametófitos verde-pálidos, prostrados, 5-7x 0,35-0,7mm. Caulídio em secção transversal com 7-8 células epidérmicas circundando 5-8 células medulares menores; merófito ventral com 2 células de largura. Ocelos incolores, 1-2 por filídio, suprabasais, dispostos lado a lado, raramente em fileira,geralmente maiores que as células adjacentes. Filídios ovalado-falcados, às vezes com uma base relativamente estreita, expandindo-se abruptamente após o lóbulo, subimbricados, com 210-350×180-300 $\mu \mathrm{m}$, ápice obtuso a fracamente agudo, margens inteiras a denticuladas, por células protuberantes; células isodiamétricas, $15-25 \mu \mathrm{m}$ diâm., trigônios conspícuos. Lóbulos ovalados, inflados, $120 \times 90 \mu \mathrm{m}$, margem livre involuta, dente apical formado por uma célula alongada, fracamente agudo e falcado, papila hialina proximal, situada entre o dente apical e a primeira célula da margem livre do lóbulo. Anfigastros distantes, orbiculares, bífidos até a 1/2 do comprimento, lobos triangulares, ápices agudos, coniventes,

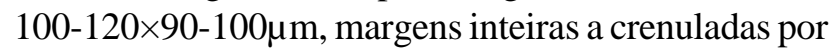
células protuberantes, às vezes com uma célula protuberante, formando um pequeno dente nas margens laterais, linha de inserção mais ou menos reta. Gemas ovaladas a oblongo-ovaladas com uma constrição mediana e rizóides marginais, retos. Androécio não observado. Ginoécio terminal ou em ramos alongados, com uma inovação do tipo pycnolejeuneóide, brácteas obovadas, geralmente do mesmo tamanho, ápice obtuso, margens fracamente crenuladas a denticulatas, lóbulos lanceolados, bractéola 3-4 vezes o comprimento de um anfigastro, inteira a emarginada, obovada, margens crenuladas a denticuladas por células fortemente cônicas e protuberantes. Perianto e esporófito não observados.

Distribuição geográfica: Costa Rica, ilhas do Caribe, Venezuela, Guiana, Guiana Francesa e Brasil, (Evans 1904; Gradstein \& Hekking 1989; Grolle 1984a; Bernecker-Lücking 1998). No Brasil, é citada para os Estados do AM e SP (Yano 1989; 1995). Primeira referência para o Estado do Pará (Ilkiu-Borges \& Lisboa 2002a).

Discussão: $C$. luteola é freqüentemente confundida com espécies do gênero Prionolejeunea, pela margem crenulada a denticulada dos filídios, porém as espécies desse gênero não possuem ocelos, o ginoécio apresenta inovação do tipo lejeuneóide e as gemas, quando presentes, são lineares. C. luteola ainda se diferencia pelos ocelos supra-basais, mas muitas vezes, dependendo do tempo em que o material foi coletado, os ocelos podem não estar mais visíveis.

Material examinado: BRASIL. Pará: Melgaço, ECFPn, 2/XII/1997, terra firme, corticícola, A.L. IlkiuBorges et al. 884 (MG); idem, 5/XII/1997, terra firme, corticícola, A.L. Ilkiu-Borges et al. 960 (MG); idem, epíxila, A.L. Ilkiu-Borges et al. 990 (MG); idem, 8/XII/1997, várzea, corticícola, A.L. Ilkiu-Borges et al. 1044 (MG); idem, A.L. Ilkiu-Borges et al. 1098 (MG); idem, A.L. Ilkiu-Borges et al. 1151 (MG).

\section{Haplolejeunea Grolle}

Grolle (1975) propôs Haplolejeunea através da espécie H. sticta Grolle, ocorrente somente em Madagascar. Posteriormente, Cheilolejeunea cucullata Steph. foi recombinada por Grolle (1979), passando a Haplolejeunea cucullata (Steph.) Grolle, que possui distribuição afro-americana. Atualmente, esse gênero apresenta somente essas duas espécies.

As espécies desse gênero são reconhecidas pelos inúmeros ocelos incolores espalhados pelos filídios, lóbulos, anfigastros, brácteas, bractéolas e perianto. Apresenta os lóbulos inflados, com dente apical ausente ou discreto, com papila hialina localizada no ápice do lóbulo, porém nem distal, nem proximal e periantos com duas quilhas (Gradstein et al. 2001). 

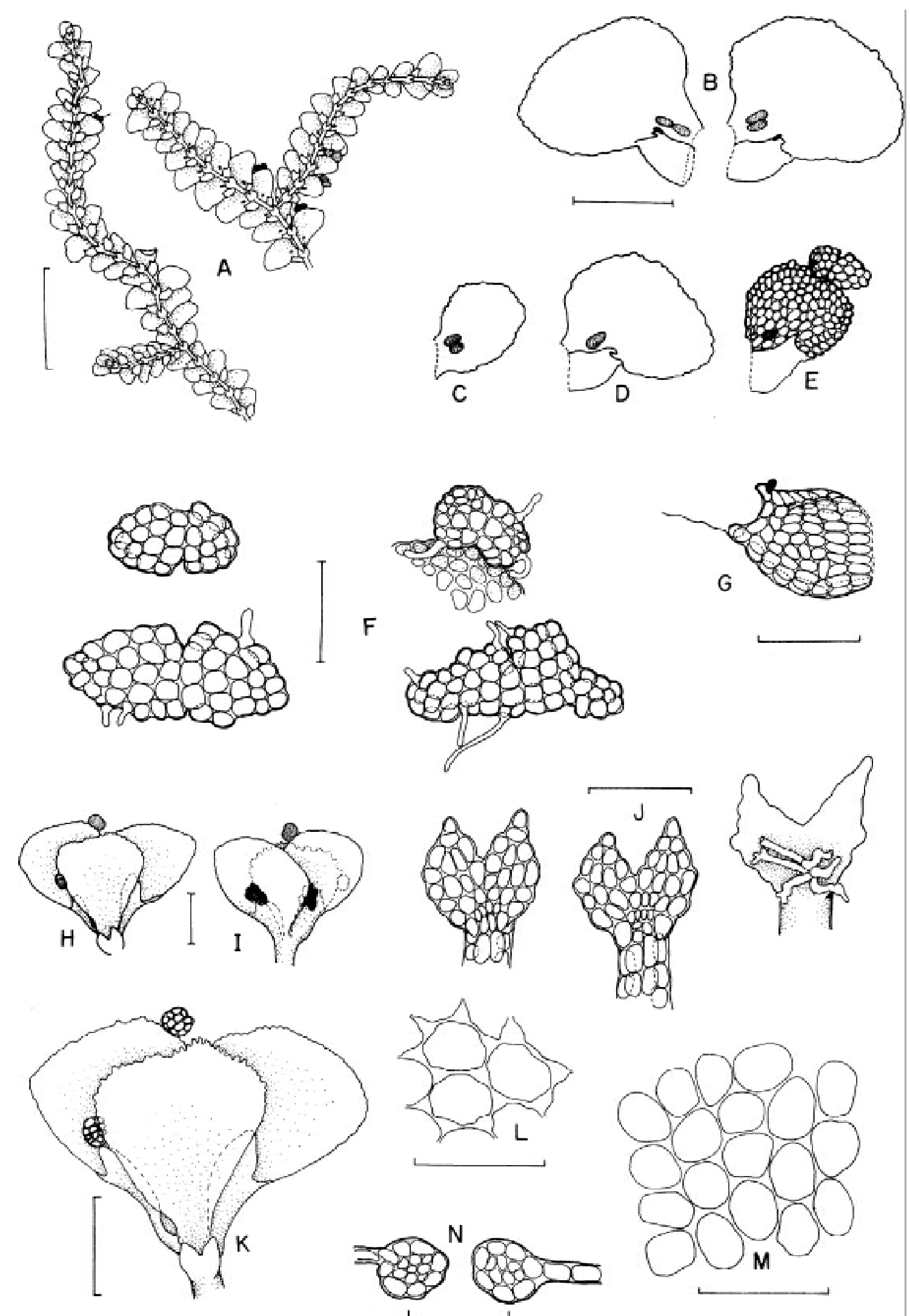

Figura 2. Cyclolejeunea luteola (Spruce) Grolle. A. Hábito, vista ventral. B. Filídios. C. Filídio com lóbulo reduzido. D. Filídio. E. Filídio com gema na margem. F. Gemas. G. Lóbulo. H. Ginoécio, vista ventral. I. Gineceu, vista dorsal. J. anfigastros. K. Gineceu. L. Células da região mediana do filídio com trigonios desenvolvidos. M. Células da região mediana do filídio com trigonios pequenos. N. Secções

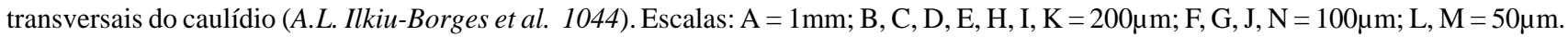


3. Haplolejeunea cucullata (Steph.) Grolle, J. Hattori, Bot. Lab., 45: 176. 1979.

Cheilolejeunea cucullata Steph., Sp. Hepat., 5: 644. 1913. Tipo: República de Camarões. Lolodorf, Staudt 99 (holótipo, G; isótipos, JE, M).

Fig. 3.

Gametófitos delicados, verde-pálidos, brilhantes, prostrados, 5-10×0,5-0,8mm. Caulídio em secção transversal com 7-8 células epidérmicas circundando 4-7 células medulares menores; merófito ventral com 2 células de largura. Ocelos incolores, do mesmo tamanho das células adjacentes, espalhados nos filídios, lóbulos, anfigastros, brácteas, bractéolas e perianto. Filídios imbricados, ovalado-falcados, margem anterior maior e fortemente arqueada, margem porterior menor, fracamente arqueada, com 270-380×230-280 $\mu \mathrm{m}$, ápice obtuso a agudo-arredondado, margens inteiras; células isodiamétricas, $10-15 \mu \mathrm{m}$ diâm., trigônios inconspícuos.

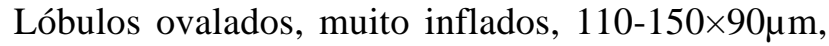
margem livre involuta na base e explanada no ápice, ápice arredondado, sem dente, papila hialina posicionada internamente no ápice, às vezes os lóbulos estão reduzidos a 2-3 células com uma papila hialina no ápice. Anfigastros distantes, oblongos, bífidos até $1 / 2$ do comprimento ou um pouco mais, lobos triangularlanceolados, ápices agudos, 60-130×40-110 $\mu \mathrm{m}$, margens inteiras, às vezes com uma célula protuberante, formando um pequeno dente lateral, linha de inserção fracamente curvada. Androécio com 2-3 pares de brácteas, bractéolas restritas à base do perigônio. Ginoécio em ramos curtos especializados, sem inovações, brácteas com tamanhos diferentes, obovadas, margens inteiras, ápice obtuso, lóbulos retangulares, bractéola oblongo-obovada, 3 vezes o comprimento de um anfigastro, bífidas em $1 / 4$ a $1 / 3$ do comprimento Periantos piriformes, 500-510x $350-450 \mu \mathrm{m}$, com 2 quilhas laterais, aladas, eretas, margens inteiras. Esporófito não observado.

Distribuição geográfica: África e América do Sul, onde foi mencionada para Guiana, Suriname e Brasil, (Gradstein \& Hekking 1989; Visnadi 1998). No Brasil é citada para o Estado de São Paulo (Schäfer-Verwimp 1992; Yano 1995). Primeira referência para a região Norte (Ilkiu-Borges \& Lisboa 2002a).

Discussão: H. cucullata é facilmente identificada pela cor clara e brilhante do gametófito, com ocelos incolores espalhados, mais visíveis nos filídios, e ainda pelos lóbulos muito inflados com ápice arredondado, sem dente apical. Na ECFPn, é preferencialmente uma espécie corticícola que ocorre em ecossistema de terra firme.
Material examinado: BRASIL. Pará: Melgaço, ECFPn, 5/XII/1997, terra firme, corticícola, A.L. Ilkiu-Borges et al. 890 (MG); idem, epíxila, A.L. Ilkiu-Borges et al. 891 (MG); idem, corticícola, A.L. Ilkiu-Borges et al. 900; idem, A.L. Ilkiu-Borges et al. 905 (MG); idem, A.L. Ilkiu-Borges et al. 921 (MG); idem, A.L. Ilkiu-Borges et al. 936 (MG); idem, A.L. Ilkiu-Borges et al. 957 (MG); idem, A.L. Ilkiu Borges et al. 966 (MG); idem, A.L. Ilkiu-Borges et al. 999 (MG); idem, A.L. Ilkiu-Borges et al. 1003 (MG); idem, 9/X/1994, terra firme, corticícola, $R$. Lisboa et al. 2506 (MG).

\section{Harpalejeunea (Spruce) Steph.}

Harpalejeunea foi inicialmente um subgênero proposto por Spruce (1885). Esse gênero tem distribuição pantropical e está bem representado na região neotropical por 12-17 espécies (Grolle \& ReinerDrehwald 1999).

As espécies de Harpalejeunea caracterizam-se por apresentar 1-3 ocelos basais ou supra-basais nos filídios (Grolle \& Reiner-Drehwald 1999) e os anfigastros emarginados ou com lobos arredondados (Schuster 1980; Gradstein et al. 2001).

Chave artificial para as espécies de Harpalejeunea

1. Filídios com ápice piliforme, formado por 6-7 células em fileira ............ 4. H. oxyphylla

1. Filídios com ápice acuminado, formado por até 2 células em fileira. 5. H. stricta

4. Harpalejeunea oxyphylla (Mont. \& Nees) Steph., in Sp. Hepat. 5: 255. 1913.

Lejeunea oxyphylla Mont. \& Nees, Ann. Sci. Nat., Bot. 55: 264. 1843. Tipo: Guiana Francesa. Cayena, Leprieur, hb. Mont., n. 297 (lectótipo, PCMont., designado por Grolle \& Reiner-Drehwald 1999; isótipo, $S)$.

Fig. 4K-T.

Gametófitos delicados, verde-pálidos, prostrados, $5-10 \times 0,6-0,7 \mathrm{~mm}$. Caulídio em secção transversal com 7 células epidérmicas circundando 3 células medulares; merófito ventral com 2 células de largura. Ocelos presentes, 1-2 por filídio, basais, pouco maiores que as células adjacentes. Filídios ovalados, contíguos a subimbricados, margem anterior maior e fortemente arqueada, margem posterior menor, mais ou menos reta a fracamente arqueada, com 290-350×150-200 $\mu \mathrm{m}$, ápice piliforme, com 6-7 células em fileira, margens inteiras; células isodiamétricas, $15-25 \mu \mathrm{m}$ diâm., trígonos 

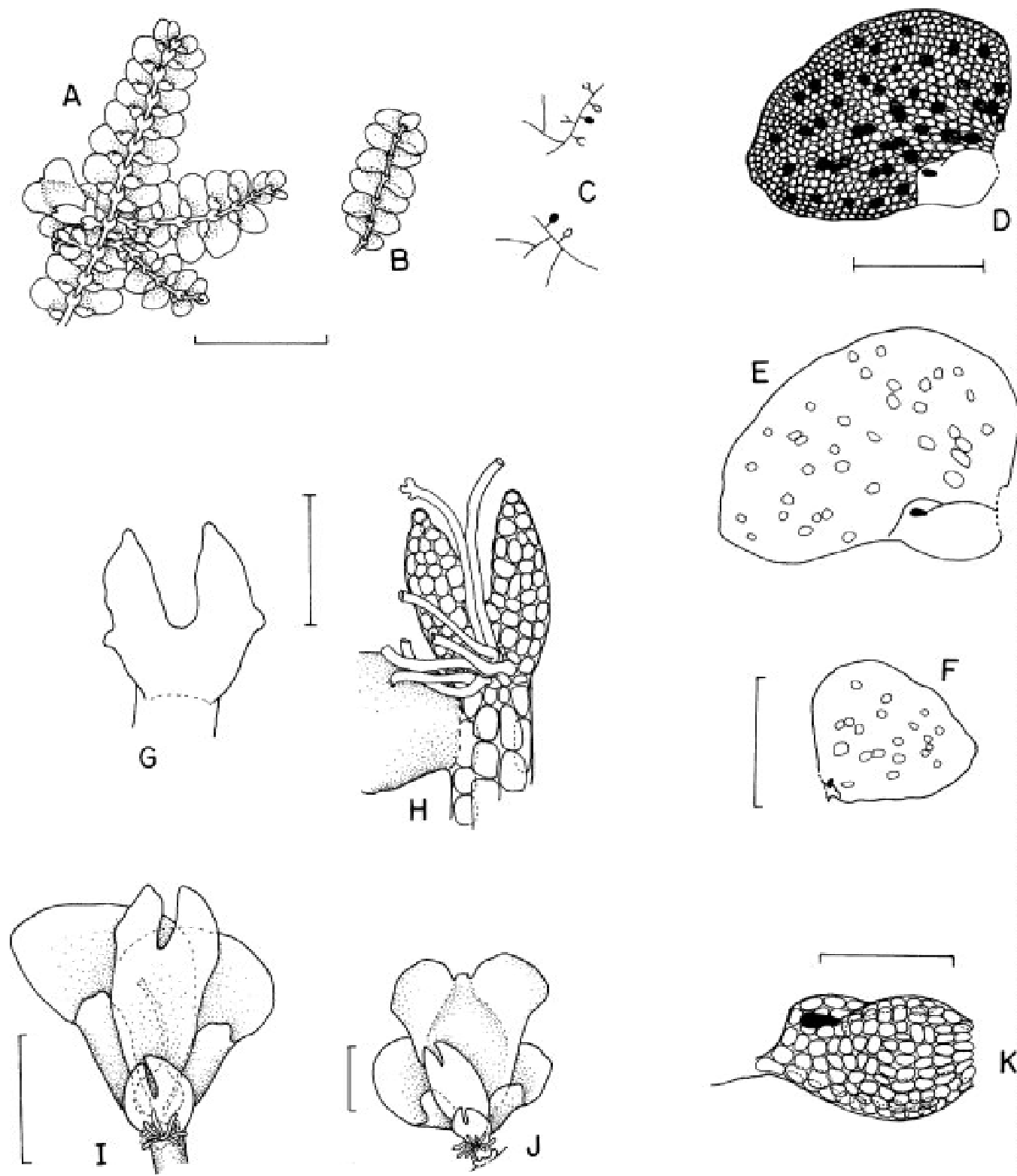

K
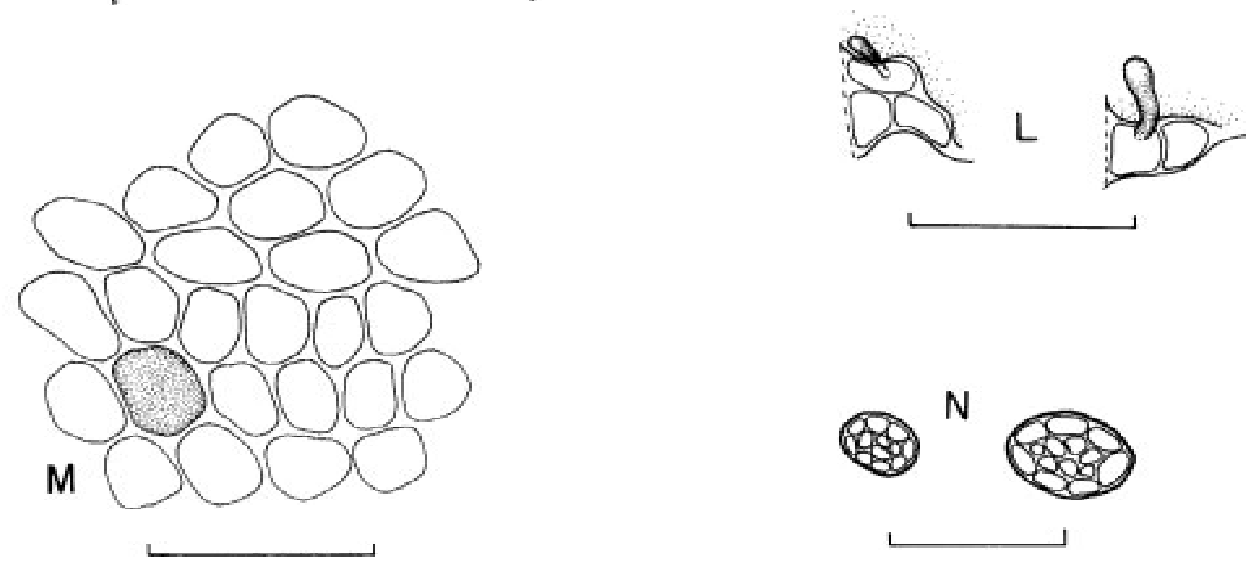

Figura 3. Haplolejeunea cucullata (Steph.) Grolle. A. Hábito com lóbulos desenvolvidos, vista ventral. B. Hábito com lóbulos reduzidos, vista ventral. C. Esquema de plantas férteis $(\mathrm{O}=$ perianto, $\bullet=$ androceu, $\mathrm{O}=$ gineceu). D-E. Filídios com lóbulos desenvolvidos. F. Filídio com lóbulo reduzido. G-H. Anfigastros. I. Gineceu. J. Perianto. K. Lóbulo, destacando papila hialina. L. Lóbulos reduzidos, destacando papilas hialinas. M. Células da região mediana do filídio. N. Secções transversais do caulídio (A. L. Ilkiu-Borges et al. 966 e 900 , apenas

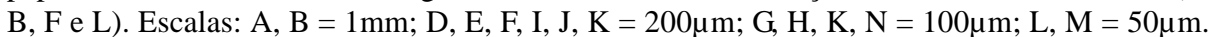


inconspícuos. Lóbulos ovalados, inflados, 130× 90-100 $\mu \mathrm{m}$, margem livre involuta na base, dente apical agudo a obtuso, formado por uma célula alongada, fracamente curvada, no ápice do lóbulo forma-se uma abertura lunulada, com um dente "pré-apical" na junção do lóbulo com o lobo do filídio, quilha fortemente arqueada, papila hialina proximal. Anfigastros distantes, cordados, brevemente bífidos, lobos arredondados, $50 \times 50 \mu \mathrm{m}$, margens inteiras, linha de inserção mais ou menos reta. Androécio, ginoécio, perianto e esporófito não observados.

Distribuição geográfica: América tropical, sendo que no Brasil é citada para AM, PA, PB, PE, BA, RJ e SP, segundo Gradstein \& Costa (2003).

Discussão: a espécie é facilmente identificada pelos filídios com o ápice abruptamente piliforme, terminando em uma fileira de até sete células.

Material examinado: BRASIL. Pará: Melgaço, ECFPn, 8/XII/1997, várzea, epífila, A.L. Ilkiu-Borges et al. 1107 (MG).

5. Harpalejeunea stricta (Lindenb. \& Gottsche) Steph., Hedwigia, 27: 291. 1888.

Lejeunea stricta Lindenb. \& Gottsche, in G. L. $\&$ N., Syn. Hep., p. 756, 1847. Tipo: Mexico. Estado de Veracruz, Mirador, Mai 1842, Liebmann 40/a' (lectótipo, C, designado por Grolle \& Reiner-Drehwald 1999; isolectótipo, W; síntipos B, BM, C, G, S, W, YU).

Fig. 4 A-J.

Gametófitos delicados, verde-pálidos, prostrados, $2-5 \times 0,4-0,5 \mathrm{~mm}$. Caulídio em secção transversal com 7-8 células epidérmicas circundando 3 células medulares; merófito ventral com 2 células de largura. Ocelos presentes, 2-3 por filídio, basais, pouco maiores que as células adjacentes. Filídios ovalados, subimbricados, margem anterior maior e fortemente arqueada, margem posterior menor, fracamente

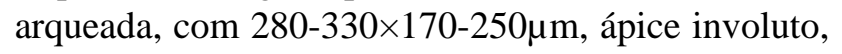
acuminado, com até 2 células em fileira, margens inteiras; células isodiamétricas, $15-25 \mu \mathrm{m}$ diâm., trigônios inconspícuos. Lóbulos ovalados, inflados, 110-130x 70-80 $\mu \mathrm{m}$, margem livre involuta, dente apical formado por 1 célula alongada, fracamente curvada, com um dente "pré-apical" na junção do lóbulo com o lobo do filídio, papila hialina proximal. Anfigastros distantes, cordados, brevemente bífidos, lobos triangulararredondados, 50-70×60-90 $\mu \mathrm{m}$, margens inteiras, linha de inserção mais ou menos reta. Androécio, ginoécio, perianto e esporófito não observados.

Distribuição geográfica: México e raramente no sul da Flórida (Schuster 1980). Grolle \& Reiner-
Drehwald (1999) acrescentaram Jamaica e Venezuela. No Brasil, foi reportada para a Bahia (Bôas \& Bastos 1998). Primeira referência para a região Norte (IlkiuBorges \& Lisboa 2002a).

Discussão: é uma espécie corticícola de vegetação aberta, suportando a exposição ao sol (Schuster 1980). $\mathrm{Na}$ ECFPn, foi coletada tanto em local exposto (vegetação savanóide), como em ambiente úmido e sombreado (várzea), mas em ambos sobre o mesmo tipo de substrato (tronco vivo). Além do ápice dos filídios em $H$. stricta serem mais curtos que em $H$. oxyphylla, essa ainda apresenta os gametófitos um pouco menores.

Material examinado: BRASIL. Pará: Melgaço, ECFPn, 8/XII/1997, várzea, corticícola, A.L. IlkiuBorges et al. 1097 (MG); idem, 4/XI/1996, vegetação savanóide, corticícola, R. Lisboa et al. 6062 (MG).

\section{Lepidolejeunea R.M. Schust.}

Este gênero foi descrito por Schuster (1963) e revisado por Piippo (1986), que descreveu, ilustrou e discutiu as 12 espécies. Posteriormente, Thiers (1987) descreveu uma espécie de Lepidolejeunea para a Austrália, elevando para 13, o número de representantes do gênero.

Lepidolejeunea é um gênero pantropical, com seis espécies ocorrendo na região neotropical (Piippo 1986). Suas espécies são reconhecidas pelos ocelos incolores espalhados nos filídios, lóbulos, anfigastros, brácteas, bractéolas e periantos, esses apresentando cinco quilhas, geralmente infladas, em alguns casos, assemelhando-se a cornos.

6. Lepidolejeunea involuta (Gottsche) Grolle, J. Hattori Bot. Lab., 55: 504. 1984.

Lejeunea involuta Gottsche, in Gottsche et al., Syn. Hep., 350. 1845. (“Lejeunia”). Tipo: St. Vicent. Hb. Lehmann, hb. Hooker (lectótipo, G, designado por Grolle 1984b; isolectótipos, G, JE, S, STR, W).

Fig. 5.

Gametófitos verde-claros a amarelados, delicados, prostrados, 10-20×0,6-1,0mm. Caulídio em secção transversal com 7-10 células epidérmicas circundando 8-13 células medulares menores; merófito ventral de 2 células de largura. Ocelos incolores, do mesmo tamanho das células adjacentes, espalhados nos filídios, lóbulos, anfigastros, brácteas, bractéolas e perianto. Filídios ovalados, involutos, sub-imbricados, 400-600x $300-400 \mu \mathrm{m}$, obliquamente dispostos no caulídio, margens anterior e posterior arqueadas até o ápice, ápice agudo, margens crenuladas a crenulado- 

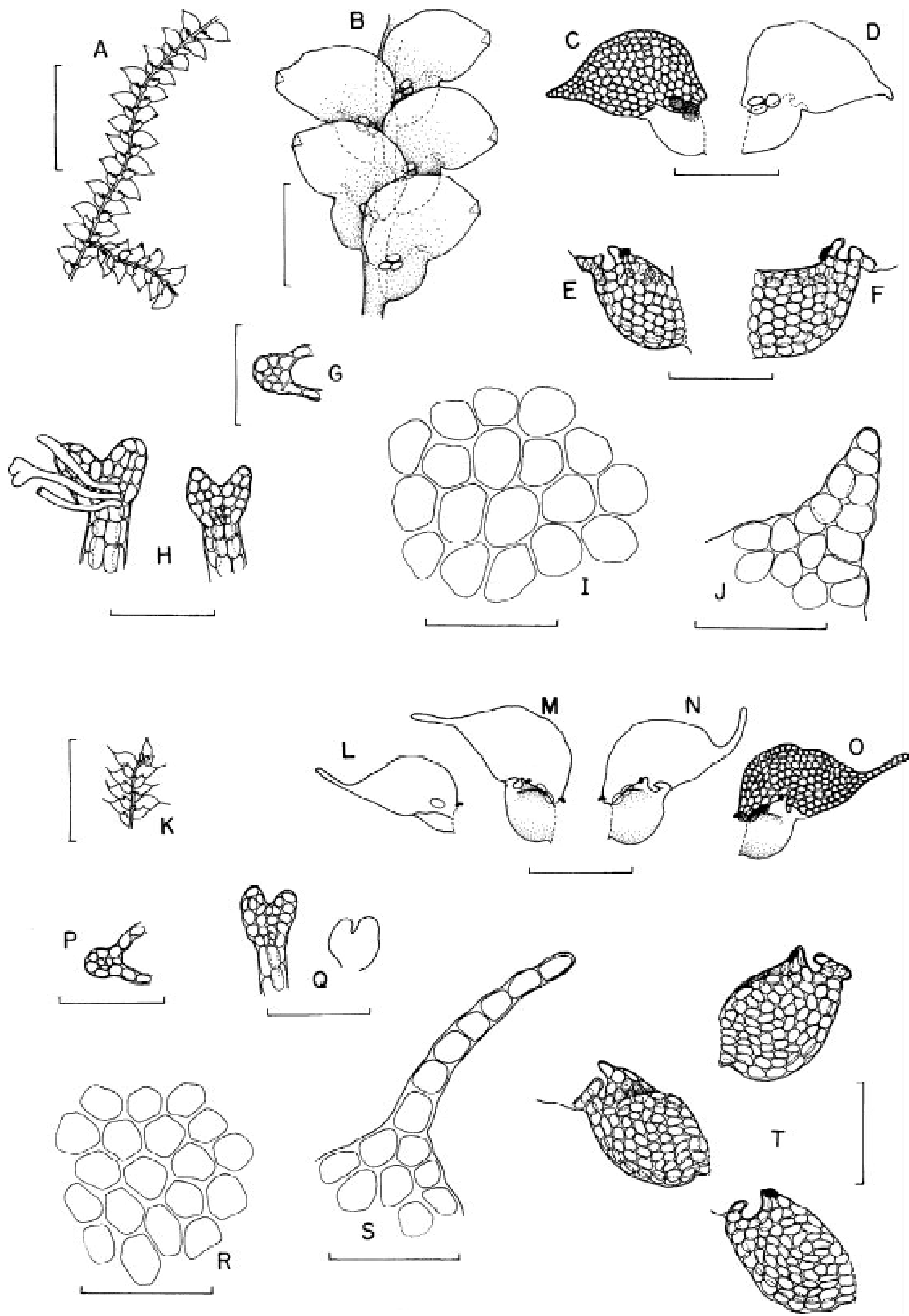

Figura 4. Harpalejeunea stricta (Lindenb. \& Gottsche) Steph. A. Hábito, vista ventral. B. Hábito, vista dorsal; C-D. Filídios. E-F. Lóbulos, destacando papila hialina. G. Secção transversal do caulídio. H. Anfigastros. I. Células da região mediana do filídio. J. Ápice do filídio (R. Lisboa et al. 6062). Harpalejeunea oxyphylla (Mont. \& Nees Steph. K. Hábito, vista ventral. L-O. Filídios. P. Secção transversal do caulídio. Q. Anfigastros. R. Células da região mediana do filídio. S. Ápice do filídio. T. Lóbulos (A.L. Ilkiu-Borges et al.

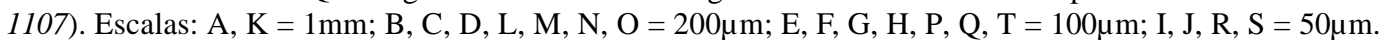


denteadas, com dentículos formados por 1 célula protuberante; células do lobo isodiamétrica-poligonais a fracamente alongadas, com 18-30×15-20 $\mu \mathrm{m}$, células marginais fracamente menores, trigônios inconspícuos, paredes delgadas. Lóbulos ovalados, inflados, 90-120×90 $\mu \mathrm{m}$, quilha do lóbulo arqueada, margem livre involuta, com 4 células alongadas curvadas para o ápice, dente apical formado por 1 célula alongada, fracamente falcada, papila hialina na base proximal do dente apical, lóbulos raramente reduzidos, estreitos, com a quilha convexa e ápice pouco definido, com um dente arredondado. Anfigastros distantes a contíguos, orbiculares, bífidos até $1 / 2$ do comprimento ou menos, lobos triangulares, ápice agudo, 200-250×200-300 $\mu \mathrm{m}$, margens crenuladas pelas células arredondadas, linha de inserção mais ou menos reta, aderido ao caulídio por 4 células, 2 células grandes, orbiculares, nas laterais e duas células menores no centro. Androécio não observado. Ginoécio em ramos laterais alongados, com 0-1 inovação do tipo pycnolejeuneóide, brácteas ovaladas, ápice agudo, lóbulos lanceolados, bractéola obovada, grande, tão longa quanto as brácteas, 3-4 vezes o comprimento de um anfigastro, bífida até $1 / 2$ do comprimento ou menos, lobos triangulares, cobrindo $1 / 2$ do perianto ou acima, margens das brácteas e bractéolas crenuladas a crenulado-denteadas. Perianto oblongo-obovado, inflado, 600-800×350-450 $\mu \mathrm{m}$, com 5 quilhas, eretas, infladas, formando cornos arredondados, rostro curto, porém conspícuo. Esporófito não observado.

Distribuição geográfica: México, Costa Rica, Cuba, Jamaica, Porto Rico, Guadalupe, Dominica, Martinica, St. Vicent, Venezuela, Guiana, Suriname, Guiana Francesa, Equador, Galápagos (Equador), Peru e Brasil (Piippo 1986; Gradstein \& Hekking 1989; Gradstein \& Costa 2003). No Brasil é mencionada para os Estados do AM, ES, PE, PR, RR, RO e SP (Grolle 1984b; Schäfer-Verwimp 1991; Yano 1989; 1995). Primeira referência para o Estado do Pará (IlkiuBorges \& Lisboa 2002a).

Discussão: essa espécie parece ser bastante comum (Piippo 1986), apresenta uma grande amplitude ecológica, podendo ocorrer em diversos tipos de ecossistemas, adotando como substrato, árvores, ramos, folhas, rochas e solo. Entretanto, na ECFPn, essa espécie foi coletada somente sobre árvore viva em um tipo de ecossistema. Nos espécimes encontrados, foi observado que os ocelos de L. involuta por serem incolores, são quase inconspícuos. Após a secagem da planta, com o passar do tempo, os ocelos tornam-se mais claros e geralmente indiferenciáveis das outras células, assim essa espécie pode ser confundida com uma espécie de outro gênero. Entretanto, os filídios com ápices agudos e, principalmente, o perianto com 5 quilhas infladas, formando cornos arredondados, são bem característicos.

Material examinado: BRASIL. Pará: Melgaço, ECFPn, 8/XII/1997, várzea, corticícola, A.L. IlkiuBorges et al. 1017 (MG); idem, A.L. Ilkiu-Borges et al. 1038 (MG); idem, A.L. Ilkiu-Borges et al. 1090 (MG); idem, A.L. Ilkiu-Borges et al. 1135 (MG).

\section{Rectolejeunea A. Evans}

Rectolejeunea é um gênero neotropical representado por, no máximo, três espécies, segundo Gradstein et al. (2001). He (1997) ao estudar Rectolejeunea berteroana, a diferenciou das outras duas espécies neotropicais, apresentando uma chave para identificação das mesmas.

Suas espécies são caracterizadas pela presença de ocelos na base do lobo do filídio, lóbulos ovalados a alongados com um longo dente apical, reprodução vegetativa por meio de filídios caducos com rizóides marginais e 1-2 inovações do tipo pycnolejeuneóide (Gradstein et al. 2001).

7. Rectolejeunea berteroana (Gottsche) A. Evans, Bull. Torrey Bot. Club, 33:12. 1906.

Lejeunea berteroana Gottsche, in Stephani, Hedwigia, 27: 282, 1888. Tipo: Porto Rico. Bertero 165 (lectótipo, G-18939, determinado por He 1997; síntipo, G, FH).

Fig. 6.

Gametófitos verde-pálidos, prostrados, frouxamente aderidos ao substrato, $5-15 \times 0,7-1,0 \mathrm{~mm}$, geralmente com ramos sem filídios, onde esses são caducos, apresentando apenas os anfigastros. Caulídio em secção transversal com 7 células epidérmicas circundando 10-12 células medulares menores; merófito ventral de 2 células de largura. Ocelos presentes, 2-3 base do lobo do filídio, maiores que as células adjacentes, inúmeros ocelos adicionais dispersos pelo lobo, um pouco maiores que as células adjacentes $(20 \mu \mathrm{m})$. Filídios ovalados, imbricados, 350-490× 270-380 $\mu \mathrm{m}$, ápice obtuso, margens inteiras, às vezes irregularmente crenulada, margem posterior com um entalhe no encontro com a quilha do lóbulo, células da

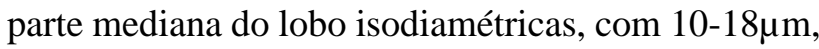
trigônios pequenos a inconspícuos. Lóbulos ovalados, inflados, $130-140 \times 80-90 \mu \mathrm{m}$, quilha do lóbulo fracamente arqueada, margem livre mais ou menos involuta na base, 

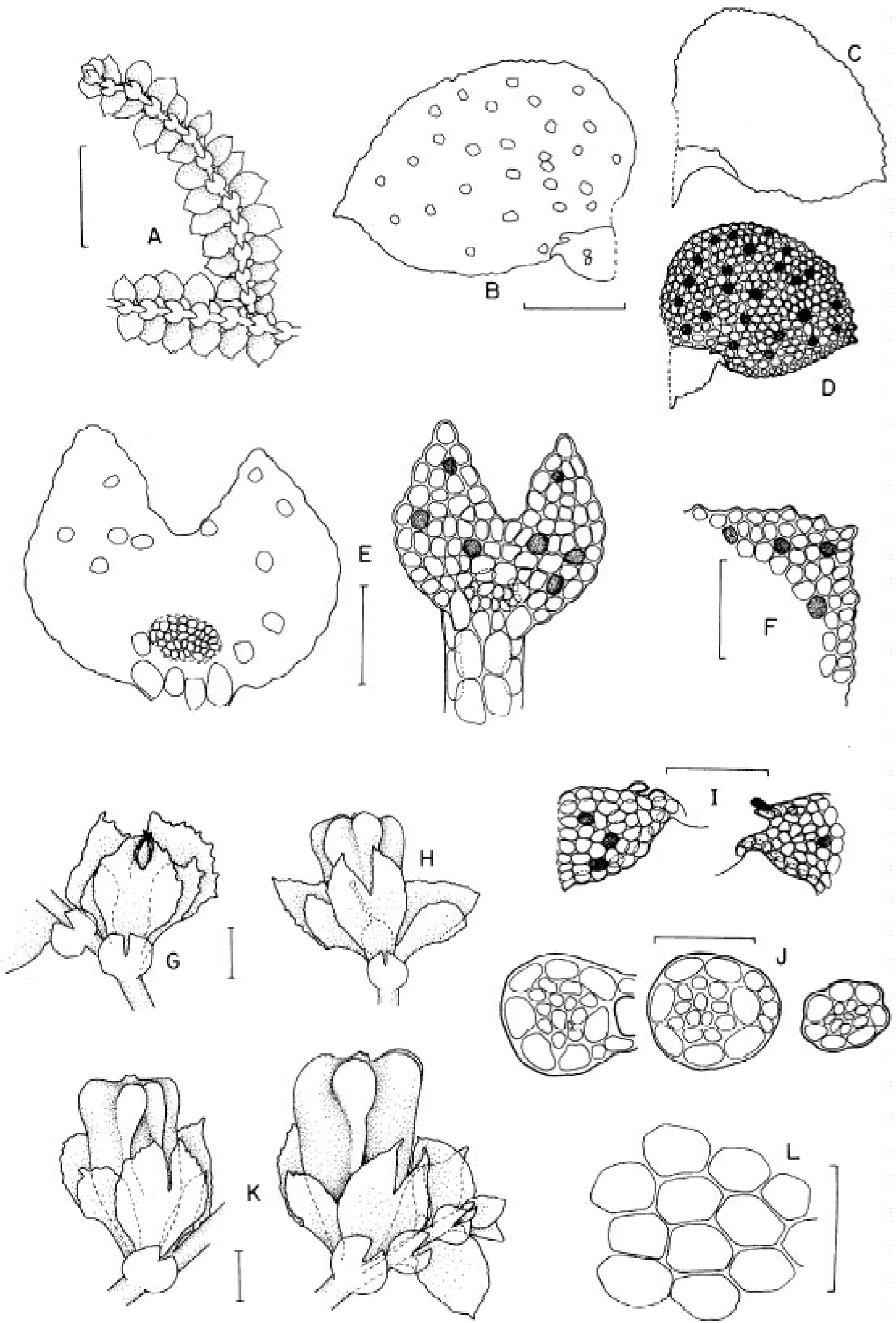

Figura 5. Lepidolejeunea involuta (Gottsche) Grolle. A. Hábito, vista ventral. B. Filídio com os ocelos destacados. C. Filídio com lóbulo reduzido. D. Filídio com células e ocelos destacados. E. Anfigastros. F. Ápice de filídio. G. Gineceu. H. Perianto. I. Lóbulos. J. Secções transversais do caulídio. K. Periantos. L. Células da região mediana do filídio (A.L. Ilkiu-Borges et al. 1090). Escalas: A = 1mm; B, C, D, $\mathrm{G}, \mathrm{H}, \mathrm{K}=200 \mu \mathrm{m} ; \mathrm{E}, \mathrm{F}, \mathrm{I}, \mathrm{J}=100 \mu \mathrm{m} ; \mathrm{L}=50 \mu \mathrm{m}$. 

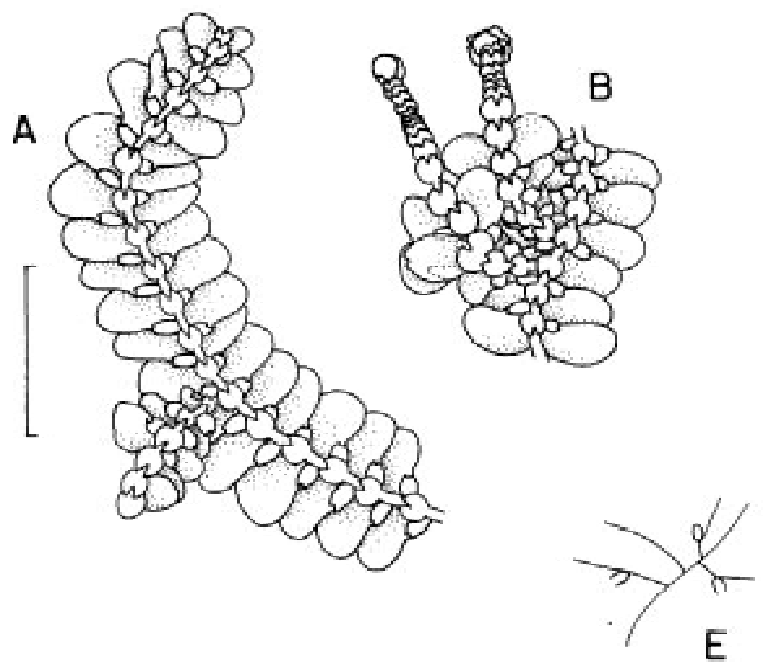

B
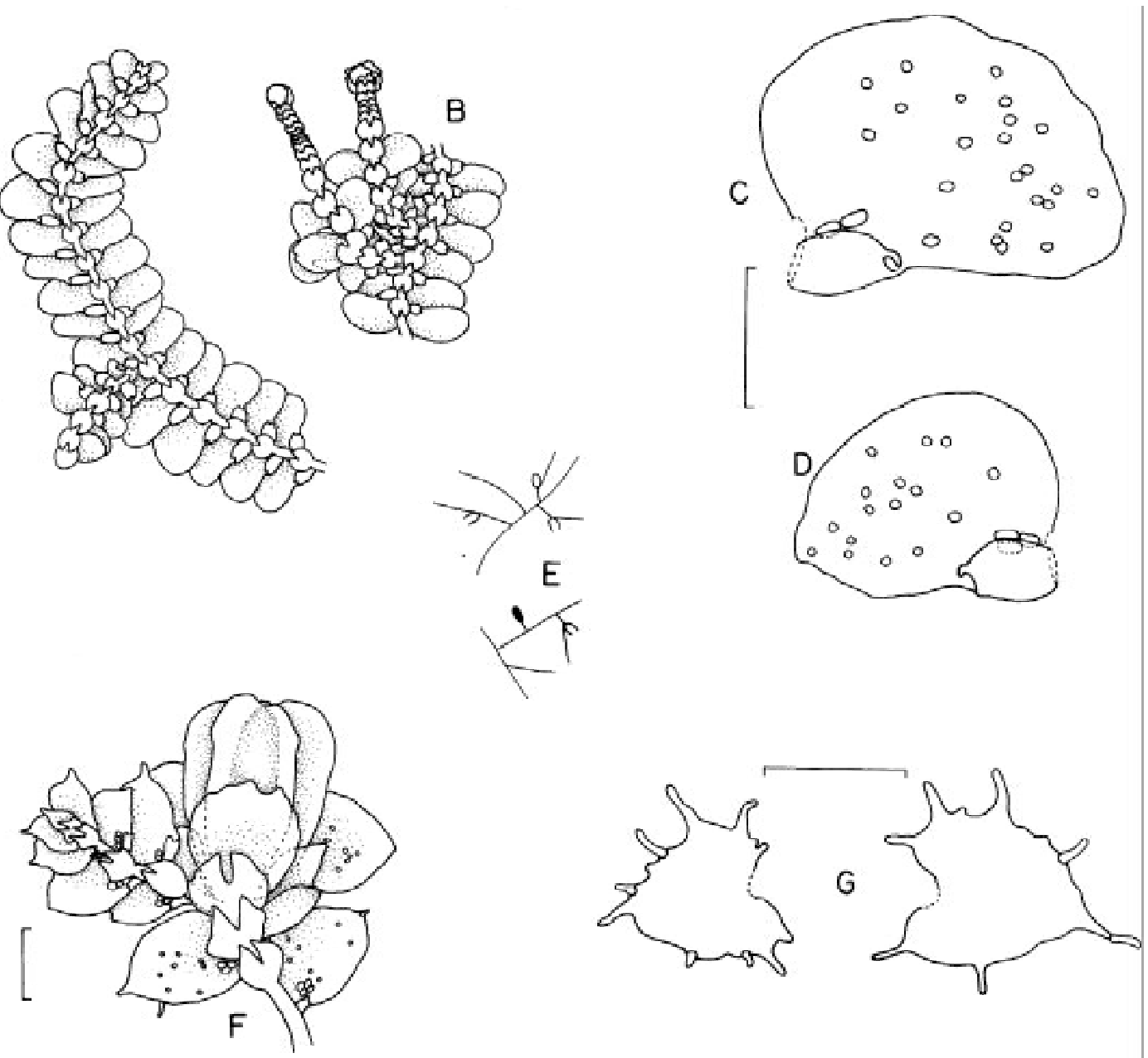

个
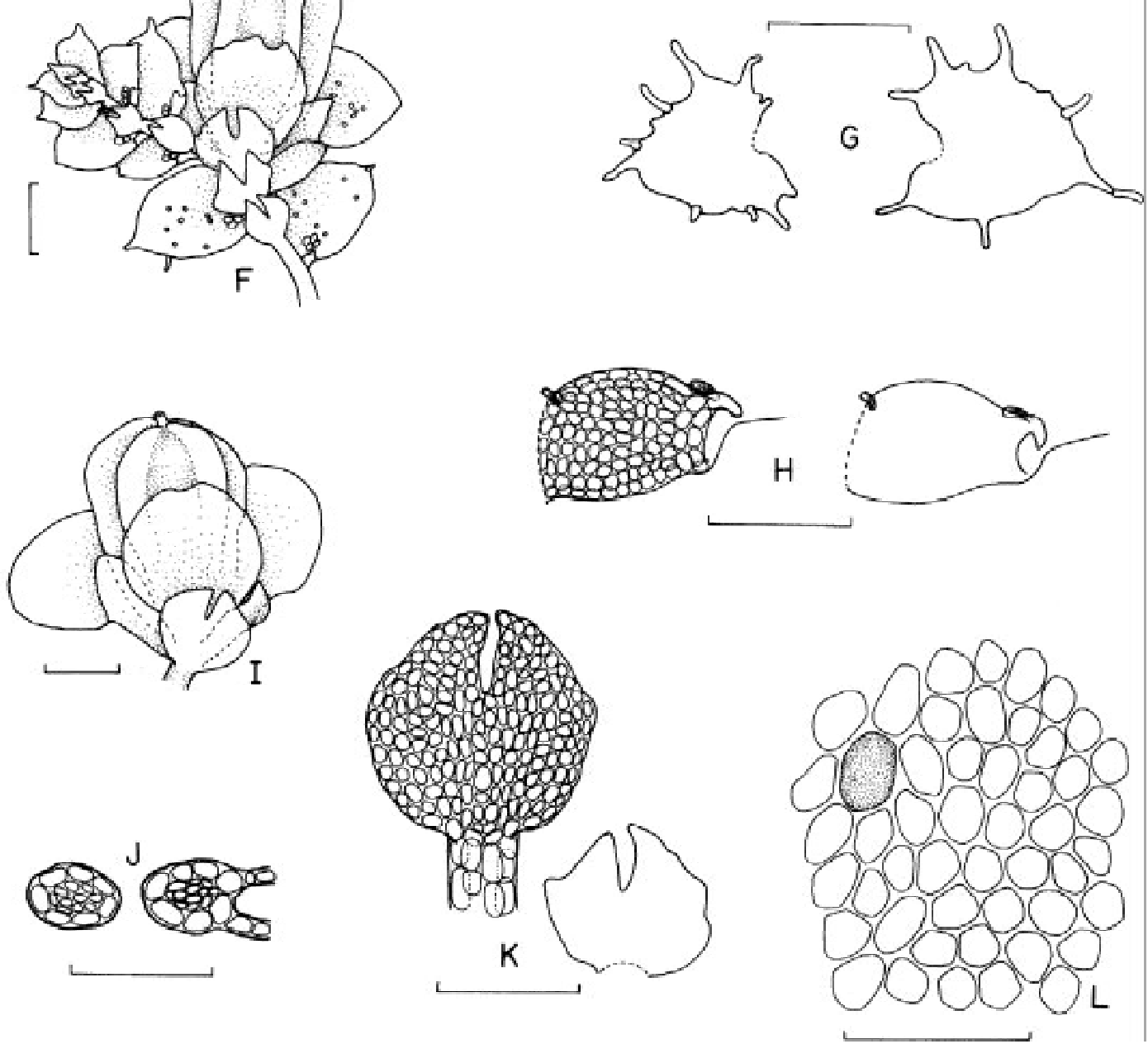

Figura 6. Rectolejeunea berteroana (Gottsche) A. Evans. A. Hábito, vista ventral. B. Hábito, com ramos de filídio caducos, vista ventral. C-D. Filídios com ocelos em destaque. E. Esquema de plantas férteis $(\mathrm{O}=$ perianto, $\bullet=$ androceu, $\mathrm{O}=$ gineceu). F. Perianto com inovação. G. Filídios caducos. H. Lóbulos. I. Perianto. J. Secções transversais do caulídio. K. Anfigastros. L. Células da região mediana do filídio

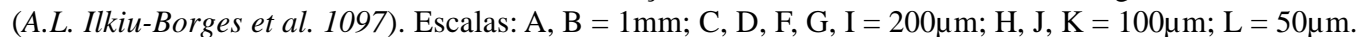


explanada no ápice, dente apical formado por uma célula longa, fortemente falcada, quase tocando a margem posterior, papila hialina proximal. Anfigastros romboidais, $100-160 \times 100-170 \mu \mathrm{m}$, com margens inteiras, às vezes formando um dente conspícuo nas margens lateriais, bífidos até $1 / 3$ do comprimento ou mais profundo, lobos eretos a convergentes, base reta a fracamente cuneada, anfigastros dos ramos com filídios caducos, menores, mais angulosos, incisão entre os lobos mais curta, fortemente imbricados. Reprodução vegetativa por meio de filídios caducos, menores que os filídios normais, com vários rizóides marginais, geralmente sem lóbulos, raramente com um lóbulo filiforme. Androécio não observado. Ginoécio em ramos alongados, com uma inovação do tipo lejeuneóide, brácteas oblongo-ovaladas, ápice obtuso a fracamente agudo, às vezes com pequenos rizóides marginais, lóbulos lanceolados, bractéola obovada, 2 vezes o comprimento de um anfigastro, emarginada a fracamente bífida, cobrindo metade do perianto ou acima. Periantos oblongo-obovados, 600-650x $400-450 \mu \mathrm{m}$, com 5 quilhas laterais, explanadas, rostro conspícuo. Esporófito não observado.

Distribuição geográfica: Estados Unidos (Flórida), México, Costa Rica, Panamá, Cuba, Porto Rico, Guadaloupe, Equador, Suriname, Guiana Francesa e Brasil (Lücking 1995; Vital \& Visnadi 1994). No Brasil é mencionada para os Estados do AC (Vital \& Visnadi 1994), AM, ES, SP (Yano 1995) e BA (Bastos \& BôasBastos 2000b). Primeira referência para o Estado do Pará (Ilkiu-Borges \& Lisboa 2002a).

Discussão: espécie corticícola, em florestas tropicais úmidas do sudeste da América do Norte, América Central e ilhas do Caribe (Schuster 1980). Distingue-se pelos filídios caducos e ramos com apenas anfigastros. Além disso, são bastante característicos os ocelos basais, os ocelos dispersos pelo lobo, esses nem sempre visíveis, e o longo dente apical dos lóbulos.

Material examinado: BRASIL. Pará: Melgaço, ECFPn, 5/XI/1996, várzea, epífila, A.L. Ilkiu-Borges et al. 702 (MG); idem, 5/XII/1997, terra firme, epíxila, A.L. Ilkiu-Borges et al. 901 (MG); idem, corticícola, A.L. Ilkiu-Borges et al. 906 (MG); idem, epífila, A.L. Ilkiu-Borges et al. 919 (MG); idem, 7/XII/1997, mata secundária, epífila, A.L. Ilkiu-Borges 1007 (MG); idem, 8/XII/1997,várzea,corticícola, A.L. Ilkiu-Borges et al. 1097 (MG); idem, A.L. Ilkiu-Borges et al. 1129 (MG); idem, epífila, A.L. Ilkiu-Borges et al. 1147 (MG); idem, 1/XI/1996, terra firme, epífila, R. Lisboa et al. 6033 (MG); idem, 4/XI/1996, várzea, corticícola,
R. Lisboa et al. 6113 (MG); idem, R. Lisboa et al. 6123 (MG).

Em mata de Várzea, ocorreram $51 \%$ dos espécimes coletados, seguidos por $45 \%$ em mata de Terra Firme e tanto a vegetação savanóide, quanto a capoeira, apresentaram $2 \%$ dos espécimes (Tab. 1). Portanto, na ECFPn, para as espécies de Lejeuneaceae aqui tratadas, os ecossistemas com maior diversidade e quantidade de espécies são ambientes de floresta primária.

$\mathrm{Na}$ ECFPn, as espécies epífilas ocorrem com alta frequiência, ainda que não acompanhada na mesma proporção pela diversidade, fazendo de folhas vivas, um substrato importante a ser observado durante as coletas. Nesse substrato registrou-se $34 \%$ dos espécimes coletados, correspondente a três espécies, enquanto que sobre tronco vivo e árvore morta, foram encontrados $57 \%$ e $9 \%$ dos espécimes coletados, o que corresponde a 6 e 4 espécies, respectivamente (Tab. 1).

Cyclolejeunea convexistipa é a mais comum entre as espécies coletadas na ECFPn, ocorrendo preferencialmente em Várzea e sobre folha viva nos dois ecossistemas onde foi coletada; enquanto C. luteola não é tão freqüente, mas apresentou igual ocorrência nos dois ecossistemas onde foi coletada e com tendência a ser corticícola.

Haplolejeunea cucullata e Rectolejeunea berteroana também são espécies comuns na ECFPn, mas enquanto a primeira ocorreu em apenas um tipo de ambiente, a segunda apresentou maior amplitude ecológica, ocorrendo em vários tipos de substrato e

Tabela 1. Número de ocorrências de Lejeuneaceae registradas em cada tipo de substrato encontrado nos quatros ecossistemas coletados na Estação Científica Ferreira Penna, PA, Brasil.

\begin{tabular}{|c|c|c|c|c|c|c|c|c|c|}
\hline \multirow[t]{2}{*}{ Ecossistemas } & \multirow[t]{2}{*}{ Substrato } & \multicolumn{7}{|c|}{ Espécies } & \multirow[t]{2}{*}{ Total } \\
\hline & & 1 & 2 & 3 & 4 & 5 & 6 & 7 & \\
\hline \multirow[t]{3}{*}{ Mata de várzea } & Tronco vivo & 1 & 3 & - & - & 1 & 4 & 4 & 13 \\
\hline & Árvore morta & 1 & - & - & - & - & - & - & 1 \\
\hline & Folhas vivas & 7 & - & - & 1 & - & - & 2 & 10 \\
\hline \multirow{3}{*}{$\begin{array}{l}\text { Mata de terra } \\
\text { firme }\end{array}$} & Tronco vivo & - & 2 & 10 & - & - & - & 1 & 13 \\
\hline & Árvore morta & - & 1 & 1 & - & - & - & 1 & 3 \\
\hline & Folhas vivas & 3 & - & - & - & - & - & 2 & 5 \\
\hline Veg. Savanóide & Tronco vivo & - & - & - & - & 1 & - & - & 1 \\
\hline Capoeira & Folhas vivas & - & - & - & - & - & - & 1 & 1 \\
\hline Total & & 12 & 6 & 11 & 1 & 2 & 4 & 11 & 47 \\
\hline
\end{tabular}

1 - Cyclolejeunea convexistipa, 2 - Cyclolejeunea luteola, 3 - Haplolejeunea cucullata, 4 - Harpalejeunea oxyphylla, 5 - Harpalejeunea stricta, 6 - Lepidolejeunea involuta, 7 - Rectolejeunea berteroana. 
ecossistemas. Entretanto, ambas ocorreram preferencialmente em ambientes primários. Entre as sete espécies estudadas, $R$. berteroana foi a única coletada em Capoeira, uma área de vegetação secundária de mais de 40 anos, já apresentando porte florestal (Lisboa et al. 1997).

As espécies de Harpalejeunea são raras na ECFPn, tanto que Harpalejeunea oxyphylla foi coletada somente uma vez em apenas um ecossistema, enquanto $H$. stricta foi coletada duas vezes em dois ecossistemas, sendo também a única das espécies aqui tratadas, coletada em área de vegetação savanóide. Essa área, estudada por Lisboa et al. (1997), é dominada pelo estrato herbáceo contínuo onde se destacam gramíneas, apresentando características de savana ou cerrado (sensu stricto), devido às pequenas árvores tortuosas e de aspecto escleromórfico; e apresenta o solo como o da várzea, hidromófico e argiloso, de origem quaternária.

Na ECFPn, Lepidolejeunea involuta ocorreu apenas em um ecossistema e em um tipo de substrato. Sobre a mesma espécie, Piippo (1986) comentou a ampla capacidade de adaptação a diferentes condições ecológicas. Para o Brasil, essa espécie também é reportada ocorrendo em vários tipos de substratos (Gradstein \& Costa 2003). Talvez com uma amostragem maior, isso venha a ser confirmado também nessa reserva.

Das sete espécies aqui tratadas, três são novas ocorrências para o estado do Pará e duas são novas para a região Norte do Brasil coletadas em Caxiuanã. Acreditamos que muito ainda pode ser acrescentado ao conhecimento da brioflora do Pará, à medida que se intensifiquem as coletas e o estudo de material dos variados ecossistemas das microrregiões e localidades do território paraense, muitos dos quais nunca foram visitados por botânicos ou especialistas em briófitas.

\section{Referências bibliográficas}

Baptista, M.L.L. 1977. Flora Ilustrada do Rio Grande do Sul. Fasc. XIII. Lejeuneaceae. Boletim do Instituto Central Biociências, série Botânica 5(36): 1-139.

Bastos, C.J.P.; Albertos, B. \& Bôas, S.B.V. 1998a. Bryophytes from some Caatinga areas in the state of Bahia (Brazil). Tropical Bryology 14: 69-75.

Bastos, C.J.P.; Stradmann, M.T.S. \& Bôas-Bastos, S. 1998b. Additional Contribution to the bryophyte flora of Chapada Diamantina National Park, State of Bahia, Brazil. Tropical Bryology 15: 15-20.

Bastos, C.J.P.; Yano, O. \& Bôas-Bastos, S. 2000. Revista Brasileira de Botânica 23(4): 357-368.
Bastos, C.J.P. \& Bôas-Bastos, S. 2000a. Some new additions to the Hepatic Flora (Jungermanniophyta) for the State of Bahia, Brazil. Tropical Bryology 18: 1-11.

Bastos, C.J.P. \& Bôas-Bastos, S. 2000b. Occurrence of some Lejeuneaceae (Jungermanniophyta) in Bahia, Brazil. Tropical Bryology 19: 45-54.

Bastos, C.J.P. \& Yano, O. 2002. Pycnolejeunea porrectiloba (Lejeuneaceae) a new species from Brazil. Nova Hedwigia 74(3-4): 439-443.

Behar, L.; Yano, O. \& Vallandro, C.G. 1992. Briófitas da restinga de Setiba, Guarapari, Espírito Santo. Boletim do Museu de Biologia Mello Leitão, Nova Série 1: 25-38.

Bernecker-Lücking, A. 1998. The Cyclolejeunea A. Evans (Hepaticae, Lejeuneceae) in Costa Rica. Phyton 38(1): 175-193.

Bescherelle, E. 1893. Liste des hépatiques récoltées aux environs de Rio de Janeiro (Brésil) par M. Glazious, et déterminées par M. Stephani. Revue Bryologique et Lichénologique 20: 59-60.

Bischler, H. 1964. Le genre Drepanolejeunea Steph. En Amérique Centrale et Méridionale. Revue Bryologique et Lichénologique 33: 15-179.

Bischler, H. 1967. Le genre Drepanolejeunea Steph. en Amérique Centrale et Méridionale-II. Revue Bryologique et Lichénologique 35: 95-134.

Bischler, H. 1968. Monographie du genre Rhaphidolejeunea Herzog. Revue Bryologique et Lichénologique 36: 56-104.

Bischler, H. 1969. Le genre Leptolejeunea (Spruce) Steph. en Amerique. Nova Hedwigia 17: 265-375.

Bôas, S.B.V. \& Bastos, C.J.P. 1998. Briófitas de uma área de Cerrado no município de Alagoinhas, Bahia, Brasil. Tropical Bryology 15: 101-110.

Costa, D.P. 1992. Hepáticas do Pico da Caledônea, Nova Friburgo, Rio de Janeiro, Brasil. Acta Botanica Brasilica 6: 3-39.

Costa, D.P. \& Yano, O. 1998. Briófitas da restinga de Macaé, Rio de Janeiro, Brasil. Hoehnea 25: 99-119.

Evans, A.W. 1902. Hepaticae of Puerto Rico. I. The species of Leptolejeunea, including an account of their vegetative reproduction. Bulletin of the Torrey Botanical Club 29: 496-510.

Evans, A.W. 1903a. Hepaticae of Puerto Rico. III. Harpalejeunea, Cyrtolejeunea, Euosmolejeunea and Trachylejeunea. Bulletin of the Torrey Botanical Club 30: $544-563$.

Evans, A.W. 1903b. Hepaticae of Puerto Rico. II. Drepanolejeunea. Bulletin of the Torrey Botanical Club 30: $19-41$.

Evans, A.W. 1904. Hepaticae of Puerto Rico. IV. Odontolejeunea, Cyclolejeunea and Prionolejeunea. Bulletin of the Torrey Botanical Club 31: 183-226.

Evans, A.W. 1905. Hepaticae of Puerto Rico. V. Ceratolejeunea. Bulletin of the Torrey Botanical Club 32: 273-290.

Evans, A.W. 1906. Hepaticae of Puerto Rico. VI. Cheilolejeunea, Rectolejeunea, Cystolejeunea and Pycnolejeunea. Bulletin of the Torrey Botanical Club 33: 1-25. 
Evans, A.W. 1907a. Hepaticae of Puerto Rico. VII. Stictolejeunea, Neurolejeunea, Omphalanthus and Lopholejeunea. Bulletin of the Torrey Botanical Club 34: 1-34.

Evans, A.W. 1907b. Hepaticae of Puerto Rico. VIII. Symbiezidium, Marchesinia, Mastigolejeunea, Caudalejeunea, and Bryopteris. Bulletin of the Torrey Botanical Club 34: 533-568.

Evans, A.W. 1908. Hepaticae of Puerto Rico. VII. Brachiolejeunea, Ptychocoleus, Archilejeunea, Leucolejeunea and Anoplolejeunea. Bulletin of the Torrey Botanical Club 35: 155-179.

Evans, A.W. 1911. Hepaticae of Puerto Rico. X. Cololejeunea, Leptocolea and Aphanolejeune. Bulletin of the Torrey Botanical Club 38: 251-286.

Evans, A.W. 1912. Hepaticae of Puerto Rico. XI. Diplasiolejeunea. Bulletin of the Torrey Botanical Club 39: $209-225$.

Germano, S.R. \& Pôrto, K.C. 1998. Briófitas epíxilas de uma área remanescente de Floresta Atlântica (Timbaúba, PE, Brasil). 2. Lejeuneaceae. Acta Botanica Brasilica 12: 53-66.

Giancotti, C. \& Vital, D.M. 1989. Flora briofítica da Reserva Biológica do Alto da Serra de Paranapiacaba, São Paulo: 1- Lejeuneaceae (Hepaticopsida). Acta Botanica Brasilica 3: 169-177.

Gradstein, S.R. 1994. Lejeunaceae: Ptychantheae, Brachiolejeuneae. Flora Neotropica, Monograph 62.

Gradstein, S.R. "1977” 1978. Studies on Lejeuneaceae subfam. Ptychanthoideae (Hepaticae) 4. Verdoornianthus, a new genus from Amazonas, Brazil. Bryologist 80: 606-611.

Gradstein, S.R. \& Costa, D.P. 2003. The Hepaticae and Anthocerotae of Brazil. Memoirs of the New York Botanical Garden 88: 1-318

Gradstein, S.R. \& Hekking, W.H.A. 1989. A Catalogue of the Bryophytes of the Guianas. I. Hepaticae and Anthocerotae. The Journal of the Hattori Botanical Laboratory 66: 197-230.

Gradstein, S.R.; Churchill, S.P. \& Salazar-Allen, N. 2001. Guide to the bryophytes of Tropical America. Memoirs of the New York Botanical Garden 86: i-viii, 1-577.

Griffin III, D. 1979. Guia preliminar para as briófitas freqüentes em Manaus e adjacências. Acta Amazonica, Suplemento 9(3): 1-67.

Grolle, R. 1975. Haplolejeunea aus Madagaskar - Eine weitere neue Gattung der Tuyamaelloideae. The Journal of the Hattori Botanical Laboratory 93: 203-210.

Grolle, R. 1979. Miscellanea hepaticologica 181-190. The Journal of the Hattori Botanical Laboratory 45: 173-183.

Grolle, R. 1984a. Zur Kenntnisder Lejeuneoideae in Cuba (1): Cyclolejeunea. Wissenchaftliche Zeitschrift der Friedrich-Schiller-Universität Jena, mathematischinaturwissenchaftlichen Reihe 33: 759-764.

Grolle, R. 1984b. Miscellanea Hepaticologica 221-230. The Journal of the Hattori Botanical Laboratory 55: 501-511.

Grolle, R. \& Reiner-Drehwald, M.E. 1999. Review of the genus Harpalejeunea (Lejeuneaceae) including the description of $H$. grandis, a new species from the páramos of Colombia. Journal of Bryology 21: 31-45.
He, X.-L. 1997. Type studies on Pycnolejeunea (Lejeuneaceae, Hepaticae), IV. Annales Botanici Fennici 34: $65-74$

He, X.-L. 1999. A taxonomic monograph of the genus Pycnolejeunea (Lejeuneaceae, Hepaticae). Acta Botanica Fennica 163: 1-77.

He, X.-L. \& Grolle, R. 2001. Xylolejeunea, a new genus of the Lejeuneaceae from the Neotropics, Madagascar and the Seychelles. Annales Botanici Fennici 38: 25-44.

Ilkiu-Borges, A.L. 2000. Lejeuneaceae (Hepaticae) da Estação Científica Ferreira Penna, município de Melgaço, Pará. Dissertação de Mestrado. Faculdade de Ciências Agrárias do Pará (UFRA), Belém. 251p.

Ilkiu-Borges, A.L. \& Lisboa, R.C.L. 2002a. Lejeuneaceae (Hepaticae). Pp. 399-419. In: P.L.B. Lisboa (org.). Caxiuanã: populações, meio físico e diversidade biológica. Belém, Museu Paraense Emílio Goeldi.

Ilkiu-Borges, A.L. \& Lisboa, R.C.L. 2002b. Leptolejeunea e Rhaphidolejeunea (Lejeuneaceae) na Estação Científica Ferreira Penna, Pará, Brasil. Acta Amazonica 32(2): 205-215.

Ilkiu-Borges, A.L. \& Lisboa, R.C.L. 2002c. Os gêneros Lejeunea e Microlejeunea (Lejeuneaceae) na Estação Científica Ferreira Penna, Estado do Pará, Brasil, e novas ocorrências. Acta Amazonica 32(4): 123-132.

Lisboa, P.L.B.; Silva, A.S.L. \& Almeida, S.S. 1997. Florística e estrutura dos Ambientes. Pp. 163-211. In: P.L.B. Lisboa (org.). Caxiuanã. Belém, Museu Paraense Emílio Goeldi.

Lisboa, R.C.L. 1976. Estudos sobre vegetacão das campinas amazônicas. V. Brioecologia de uma campina amazônica. Acta Amazonica 6: 171-191.

Lisboa, R.C.L. 1985. Avaliação da brioflora de uma área de floresta de terra firme. II - Hepaticae. Boletim do Museu Paraense Emílio Goeldi, Série Botânica 2(1): 99-114.

Lisboa, R.C.L. 1993. Musgos Acrocárpicos do Estado de Rondônia. Belém, Museu Paraense Emílio Goeldi, 272p.

Lisboa, R.C.L. \& Ilkiu-Borges, A.L. 1995. Diversidade das briófitas de Belém (PA) e seu potencial como indicadoras de poluição urbana. In: Anais da I Reunião de Botânicos da Amazônia, 1995. Boletim do Museu Paraense Emílio Goeldi, Série Botânica 11(2): 199-225.

Lisboa, R.C.L. \& Nazaré, J.M.M. 1997. A Flora Briológica. Pp. 221-233. In: P.L.B. Lisboa (org.). Caxiuanã. Belém, Museu Paraense Emílio Goeldi.

Lisboa, R.C.L. \& Yano, O. 1987. Novas ocorrências de briófitas na Amazônia brasileira. Boletim do Museu Paraense Emílio Goeldi, Série Botânica 3: 141-156.

Lücking, A. 1995. Diversität und Mikrohabitatpräferenzen epiphyller Moose in einem tropichen Regenwald in Costa Rica. Dissertation zur Erlangung des Doktorgrades. Universidade de Ulm, Ulm. 211p.

Pôrto, K.C. 1989. Analyse floristique et de la bryoflore d'une forêt de plaine et d'une forêt d'altitude moyenne dans l'état de Pernambuco (Brésil). Thèse Doct. Sci. Univ. Paris XII, Val de Marne.

Pôrto, K.C. 1990. Bryoflores d'une forêt de plaine et d'altitude moyenne dans l'état de Pernambuco (Brés.): Analyse floristique. Cryptogamie, Bryologie Lichénologie 11: 109-161. 
Pôrto, K.C. \& Grolle, R. 1987. Drepanolejeunea bischleriana sp. nov. du Brésil. Cryptogamie, Bryologie Lichénologie 8: 301-304.

Pôrto, K.C.; Gradstein, S.R.; Yano, O.; Germano, S.R. \& Costa, D.P. 1999. New or interesting reccords of Brazilian bryophytes. Tropical Bryology 17: 39-45.

Piippo, S. 1986. A monograph of the genera Lepidolejeunea and Luteolejeunea (Lejeuneaceae, Hepaticae). Acta Botanica Fennica 132: 1-69.

Reiner-Drehwald, M.E. 1993. Las Lejeuneaceae (Hepaticae) de Misiones, Argentina. I. Las especies holostipas Tropical Bryology 7: 13-45.

Reiner-Drehwald, M.E. 1994. Las Lejeuneaceae (Hepaticae) de Misiones, Argentina. II. Cololejeunea. Tropical Bryology 9: 79-88.

Reiner-Drehwald, M.E. 1995a. Las Lejeuneaceae (Hepaticae) de Misiones, Argentina. III. Drepanolejeunea y Leptolejeunea. Tropical Bryology 10: 21-27.

Reiner-Drehwald, M.E. 1995b. Las Lejeuneaceae (Hepaticae) de Misiones, Argentina. IV. Aphanolejeunea. Tropical Bryology 10: 29-39.

Reiner-Drehwald, M.E. 1998. Las Lejeuneaceae (Hepaticae) de Misiones, Argentina. V. Cheilolejeunea y Lepidolejeunea. Tropical Bryology 14: 53-68.

Reiner-Drehwald, M.E. \& Goda, A. 2000. Revision of the genus Crossotolejeunea (Lejeneaceae, Hepaticae). The Journal of the Hattori Botanical Laboratory 89: 1-54.

Reiner-Drehwald, M.E. \& Gradstein, S.R. 1995. Myriocoleopsis riparia (Lejeuneaceae), a new species from south-eastern Brazil and north-eastern Argentina. Journal of Bryology 18: 479-484.

Reiner-Drehwald, M.E. \& Schäfer-Verwimp, A. 1996. Drepanolejeunea grollei (Lejeuneaceae, Hepaticae), a new species from south-eastern Brazil. Candollea 51: 475-482.

Schuster, R.M. 1963. An annotated Synopsis of the Genera and Subgenera of Lejeuneaceae. I. Introduction; annotated keys to subfamilies and genera. J. Cramer, Weinheim.

Schuster, R.M. 1980. The Hepaticae and Anthocerothe of North America. East of the Hundredth Meridian. v. 4, Columbia University Press, New York.

Oliveira e Silva, M.I.M.N. 1998. Briófitas da Reserva Ecológica de Rio das Pedras, município de Mangaratiba, do Parque Estadual da Ilha Grande e da Reserva Biológica Estadual da Praia do Sul, município de Angra dos Reis, Estado do Rio de Janeiro. Tese de Doutorado, Universidade de São Paulo, São Paulo. 321p.

Oliveira e Silva, M.I.M.N. \& O. Yano. 1998. Ocorrências novas de briófitas para o Brasil. Revista Brasileira de Botânica 21(2): 125-134.

Schäfer-Verwimp, A. 1991. Contribution to the knowledge of the bryophyte flora of Espírito Santo, Brazil. The Journal of the Hattori Botanical Laboratory 69: 147-170.
Schäfer-Verwimp, A. 1992. New or interesting records of Brazilian bryophytes, III. The Journal of the Hattori Botanical Laboratory 71: 55-68.

Spruce, R. 1884-1885. Hepaticae Amazonicae et Andinae. Jubulae. Transactions and Proceedings of the Botanical Society 15: i-xi, 1-588.

Thiers, B.M. 1987. Lepidolejeunea queenslandica (Lejeuneaceae Subfamily Lejeuneoidea): A New Species from Australia. Memoirs of the New York Botanical Garden 45: 556-560.

Visnadi, S.R. 1998. Briófitas em ecossistemas costeiros do Núcleo Picinguaba do Parque Estadual da Serra do Mar, Ubatuba, SP. Tese de Doutorado. Universidade Estadual Paulista, São Paulo. 273p.

Visnadi, S.R. \& Monteiro, R. 1990. Briófitas da cidade de Rio Claro, Estado de São Paulo, Brasil. Hoehnea 17: 71-84.

Visnadi, S.R. \& Vital, D.M. 1995. Bryophytes from restinga in Setiba State Park, Espírito Santo State, Brazil. Tropical Bryology 10: 69-74.

Vital, D.M. \& Visnadi, S.R. 1994. Bryophytes of Rio Branco Municipality, Acre, Brasil. Tropical Bryology 9: 69-74.

Vital, D.M.; Giancotti, C. \& Pursell, R.A. 1991, The bryoflora of Fernando de Noronha, Brazil. Tropical Bryology 4: 23-24.

Yano, O. 1984a. Checklist of Brazilian liverworts and hornworts. The Journal of the Hattori Botanical Laboratory 56: 481-548.

Yano, O. 1984b. Briófitas. In: O. Fidalgo \& V.L.R. Bononi (coord.). Técnicas de coleta, preservação e herborização de material botânico. (Manual, 4) Instituto de Botância, São Paulo.

Yano, O. 1987. Addittions to the Brazilian Hepaticae. Bryologist 90: 374-375.

Yano, O. 1989. An additional checklist of Brazilian bryophytes. The Journal of the Hattori Botanical Laboratory 66: 371-434.

Yano, O. 1993. Briófitas do nordeste brasileiro: Estado da Paraíba, Brasil. Biologica Brasilica 5(1/2): 87-100.

Yano, O. 1995. A new additional annotated checklist of Brazilian bryophytes. The Journal of the Hattori Botanical Laboratory 78: 137-182.

Yano, O. 1996. A checklist of Brazilian bryophytes. Boletim do Instituto de Botânica 10: 47-232.

Yano, O. \& Andrade-Lima, D. 1987. Briófitas do nordeste brasileiro: Estado de Pernambuco. Revista Brasileira de Botânica 10: 171-181.

Yano, O. \& Lisboa, R.C.L. 1988. Briófitas do território Federal do Amapá, Brasil. Boletim do Museu Paraense Emílio Goeldi, Série Botânica 4: 243-270.

Yano, O. \& Mello, Z.R. 1992. Briófitas novas para o Estado de Roraima, Brasil. Acta Amazonica 22(1): 23-50. 